FREITAS, Talita da Silva Clerc; MELLO, Ruth Espíndola de. Curso de Negócios de Impacto Socioambiental da PUC Rio: uma ferramenta de fomento e disseminação do Empreendedorismo Social.

\title{
Curso de Negócios de Impacto Socioambiental da PUC Rio: uma ferramenta de fomento e disseminação do Empreendedorismo Social
}

The effect of an Extension Course on Social and Environmental Impact Business: a case study

\section{Talita da Silva Clerc de Freitas}

talitaclerc@gmail.com

Graduanda de Psicologia na PUC-Rio com Domínio Adicional de Empreendedorismo e em Trabalho e Contemporaneidade.

\section{Ruth Espíndola de Mello (Orientadora) rruthesmello@gmail.com}

Doutora em Ciências Sociais pela PUC-Rio, mestre em Desenvolvimento, Agricultura e Sociedade pela UFRRJ (2006), especialista em Políticas Públicas e Governo pelo IUPERJ (2003) e graduada em Ciências Econômicas pela UFRJ (2000)

\section{Resumo}

O objetivo deste artigo é apresentar um campo de organizações ainda pouco conhecido: os Negócios de Impacto Socioambiental Positivo (NISAP). Serão apresentada a composição e a estrutura desse sujeito que estaria inaugurando um setor "novo", o Setor 2,5. Será ainda abordada a importância das estratégias de programas de aprendizagem, como cursos, oficinas e diferentes formas de fomento na formação de profissionais e empreendedores nesse campo. Desse modo, situar o lócus do campo do conhecimento da educação é a melhor forma de mudar a visão de mundo e as formas de se viver.

Palavras-chave: empreendedorismo; negócios; impacto; educação; transformação social.

\begin{abstract}
The purpose of this article is to present a little-known business possibility: the Social and Environmental Business (EIB, as abroad is nown). From this, the composition and structure of this "new" sector will be presented and the importance of learning strategies, such as courses, workshops and different forms of development, in the training of professionals in this field, thus highlighting how education is the best way to change the worldview.
\end{abstract}


FREITAS, Talita da Silva Clerc; MELLO, Ruth Espíndola de. Curso de Negócios de Impacto Socioambiental da PUC Rio: uma ferramenta de fomento e disseminação do Empreendedorismo Social.

Keywords: entrepreneurship; business; impact; education; transformation.

\section{Introdução}

Nos últimos anos, a temática do empreendedorismo ganhou mais espaço no mercado e nas universidades em razão da necessidade de reinvenção ou em consequência das crises financeiras enfrentadas pelo mundo. Diversos elementos compõem a realidade empreendedora: alguns dizem que a personalidade é o que mais pesa; outros, que são as oportunidades, conforme o senso comum afirma. Todavia, o empreendedor, principalmente no Brasil, surge da necessidade de mudança, seja por motivações financeiras, seja por questões de engajamento pessoal (GEM, 2008 apud Fagundes; Fagundes, 2009). Dessa forma, os empreendedores seguem a máxima atribuída a Schopenhauer (1851) sobre trabalho e tarefa: "eles olham para algo que todos veem, mas pensam em uma alternativa totalmente diferente e a colocam em prática".

O Empreendedorismo Social é um dos principais frutos da mentalidade empreendedora que vem conquistando o cenário atual. Inaugurado com Mohammad Yunus (1976), o pai do microcrédito, o Empreendimento Social traz uma nova forma de agir, pois envolve questões sociais associadas com estruturas financeiras. Tais empreendimentos e empreendedores buscam ter um impacto positivo na sociedade sem deixar de ser sustentável financeiramente. No caso das empresas sociais que se posicionam como Modelo Yunus, o lucro obtido é utilizado para retroalimentar o sustento organizacional e para aumentar a escala da operação e dos beneficiários. Os Negócios Sociais passam a ter uma maior autonomia e estrutura, permitindo que seu crescimento seja cada vez mais relevante e produza mais benefícios para a sociedade.

Contudo, surgiu uma nova forma de enxergar esses empreendimentos: os Negócios de Impacto Socioambiental, que têm certas particularidades diferenciadas em relação ao Modelo Yunus, mas tais particularidades fogem dos objetivos desta investigação. O principal objetivo de tais empreendimentos é a busca pelo impacto, atrelada ao desenvolvimento de um produto/serviço que atenda às demandas do mercado e possa ser rentável, unindo assim o $2^{\circ}$ Setor com o $3^{\circ}$ Setor, originando o conhecido "Setor 2,5 ".

A união do social com o financeiro evidencia que o mercado pode mudar. Cada vez mais no Brasil aumenta o número de empreendedores que têm sustentabilidade ambiental, como visto na matéria on-line (Pensamento Verde, 2013), além do fim das desigualdades e outras questões como objetivo, sem deixar de visar buscar autonomia financeira das organizações. Entretanto, há uma necessidade de qualificar as pessoas para que elas entendam o porquê dessa mudança ser necessária; afinal, os governos e o mercado mundial precisam mudar, uma vez que o planeta não aguentará o ritmo atual, como apontado na Conferência das Nações Unidas sobre 
FREITAS, Talita da Silva Clerc; MELLO, Ruth Espíndola de. Curso de Negócios de Impacto Socioambiental da PUC Rio: uma ferramenta de fomento e disseminação do Empreendedorismo Social.

as Mudanças Climáticas (2015). Dessa forma, tornou-se missão de muitos empreendedores estruturarem projetos e empresas que possam ajudar a influenciar diversos grupos locais, que, quando somados a outros projetos, provoquem um "efeito cascata". Pensando nesse grande boom dos chamados "NIS", a PUC-Rio iniciou um projeto inovador, coordenado pela Profa. Dra. Ruth Espíndola, para instruir e fomentar esse campo de atuação.

O fomento é um dos principais passos para propagar a mentalidade empreendedora de impacto, já que, por intermédio de cursos, workshops e mentorias, os conhecimentos desse novo campo são passados e as conexões são formadas. O "Curso de Negócios de Impacto Socioambiental" da PUC-Rio, iniciado em 2019, inaugurou uma nova proposta de formação de cidadãos por meio de um ensino completo, que contempla todas as etapas e processos que envolvem o Empreendedorismo de Impacto.

Por ser um cenário pioneiro e de qualidade, tornou-se interessante compreender a influência que esse curso tem na vida e na visão de seus alunos. Dessa forma, este artigo visa analisar o efeito que o Curso de NIS da PUC-Rio tem na visão de mercado de seus alunos. Tal estudo será desenvolvido por meio de análise documental e dos dados obtidos por pesquisas qualitativas anônimas feitas na metade e no final da $3^{\mathrm{a}}$ edição do curso.

A educação, como dito por Paulo Freire (1979), não muda o mundo, mas sim as pessoas, e essas causam mudanças na sociedade. No contexto atual, é preciso que haja transformações nas relações do ser humano, pois o planeta está em seu limite e as pessoas estão sofrendo, afetadas por inúmeros problemas sociais. Por isso, torna-se necessário que surjam cada vez mais empreendedores sociais, para que eles possam agir conforme Schopenhauer (1851) afirmava.

\section{Empreendedorismo X Empreendedorismo Social}

O empreendedorismo envolve um processo dinâmico que está relacionado à geração de riquezas, sendo capaz de provocar transformações sociais, políticas, culturais e econômicas (Farah, 2008 apud Fagundes; Fagundes, 2009). Com manifestações desde o início das sociedades, o empreendedorismo busca trazer inovações para a coletividade, ainda que tenha sido refinado e ampliado com o tempo (Hisrich, 2009 apud Fagundes; Fagundes, 2009). O empreendedor é um agente em sua sociedade, provocador de grandes impactos; todavia, ele não deixa de ser afetado por ela, ocasionando, então, mudanças nas definições com o decorrer dos anos e da evolução e desenvolvimento social.

No século XIX, Jean-Baptiste Say inseriu o termo empreendedorismo na teoria da economia para referir-se às pessoas que criam valor ao redirecionar recursos financeiros e intelectuais de 
FREITAS, Talita da Silva Clerc; MELLO, Ruth Espíndola de. Curso de Negócios de Impacto Socioambiental da PUC Rio: uma ferramenta de fomento e disseminação do Empreendedorismo Social.

forma inovadora a fim de aumentar a produtividade (Dees, 2001; Hindle, 2008). Todavia, foi nos anos 1950 que o empreendedor, por intermédio de Schumpeter, passa a ser associado a um agente de mudança econômica, capaz de identificar oportunidades (Parente et al., 2011). O "perfil empreendedor" passou a ser algo muito estudado, gerando diferentes visões e alguns mitos. Entretanto, conforme afirmado na obra de Fagundes e Fagundes (2009), há diversos perfis de empreendedores, visto que eles podem surgir em contextos e com formações diferenciadas. Portanto, o que define o empreendedor é (i) sua iniciativa e paixão aplicadas à sua proposta de negócio, utilizando os recursos disponíveis e transformando o ambiente em que vive; e (ii) a assunção de riscos, por ele saber que há a possibilidade de sua ideia não ser consolidada.

O empreendedorismo social é uma ramificação do conceito de empreendedorismo visto a priori, mas cuja finalidade não é a acumulação de lucro (Parente et al., 2011). Nesse sentido, é considerado um tipo de empreendedor que tem como missão criar e maximizar o valor social, ao invés da geração de riquezas típica (Davis, 2002; Austin et al., 2006; Certo; Miller, 2008 apud Parente et al., 2011).

\section{Origens}

A flexibilidade dinâmica do conceito de empreendedorismo ocasiona dificuldade em determinar uma definição exata devido ao excesso de significado (Weinert, 2001 apud Parente et al., 2011), que é consequência da construção contínua feita acadêmica e socialmente. O Empreendedorismo Social, desse modo, acaba sendo impactado por essa constante atualização. Contudo, pode-se afirmar que seus processos e práticas procuram incorporar ideias de negócios como instrumento de inovação que ajudariam a superar desafios sociais (Parente et al., 2011).

As raízes do Empreendedorismo Social, segundo Dees (2009 apud Parente et al., 2011), remontam à era vitoriana tardia, final do século XIX, período de ascensão da "Caridade Científica" que inaugura uma nova visão de caridade que deixa de ser baseada em "dar esmolas", visando mudanças duradouras.

No século seguinte, os estudos voltados para o Empreendedorismo Social alcançam novas perspectivas baseadas em duas diferentes escolas: a Escola Norte-americana e a Escola Europeia (Parente et al., 2011). A primeira escola foi influenciada pela concepção de organizações sem fins lucrativos e por fenômenos como cultura, conhecimento e práticas empreendedoras, marcada por políticas como as do Pós-Segunda Guerra e as do New Deal, quando o Estado se volta para as demandas sociais e busca satisfazê-las (Defourny, 2001 apud Parente et al., 2011). A Escola Europeia, por sua vez, é marcada por uma visão do Estado como provedor dos serviços que 
FREITAS, Talita da Silva Clerc; MELLO, Ruth Espíndola de. Curso de Negócios de Impacto Socioambiental da PUC Rio: uma ferramenta de fomento e disseminação do Empreendedorismo Social.

solucionam as questões sociais, diferentemente do contexto norte-americano. Nesse seguimento, a tradição é o conceito de economia social, uma vez que o terceiro setor possui certa autonomia e estruturação (Parente et al., 2011). Em ambas as escolas, é adotada uma visão do empreendedor como agente de mudança que irá desencadear transformações sociais. No entanto, na americana isso será o foco principal, enquanto na europeia a face econômica é tão importante quanto a social, assim, aproximando-se mais dos NIS que serão explorados a posteriori.

No Brasil, o Empreendedorismo Social é tratado como fruto de um estreitamento do empreendedorismo social e da lógica empresarial que desencadeia maior participação das empresas (Oliveira, 2004) que, por ser um assunto em constante mutação, acaba tendo poucas fontes, como artigos e trabalhos acadêmicos, ainda que seja um cenário em constante mudança.

\section{Definição}

O aumento da desigualdade social e o desgaste dos recursos naturais são consequências do modelo econômico vigente e da mentalidade de consumo. O Empreendedorismo Social surge, assim, como uma resposta a esses desafios, a fim de gerar valor social e ambiental além do econômico. Segundo Austin, Stevenson e Wei-Skillern (2006 apud Rosolen; Comini, 2014), o Empreendedorismo Social pode ser definido como uma atividade inovadora, cujo objetivo é social e pode estar situado no setor privado, no terceiro setor ou em organizações híbridas, também conhecidas como Setor 2,5. Ou seja, o Empreendedorismo Social seria a união da criação de valor social por meio de inovações que podem gerar lucro, mas geram também transformação social.

O termo Negócios Sociais destacou-se por meio de Muhammad Yunus, o criador do Grameen Bank e grande disseminador desse tipo de empreendimento. Segundo Yunus, Mointgeon e Lehmann-Ortega (2010 apud Rosolen; Comini, 2014), os Negócios Sociais (NS) não visam o lucro para si, mas o resgate do investimento inicial, se necessário, e o reinvestimento dos excedentes a fim de manter o NS, reduzindo preços e melhorando a qualidade. Sendo assim, diferenciam-se dos negócios tradicionais, uma vez que seu maior objetivo é atender a sociedade e melhorar as condições de vida, além de buscar a retroalimentação de suas operações.

No Brasil e em outros países latino-americanos, os Negócios Sociais receberam variações em sua terminologia, como Negócios com Impacto Social e Negócios de Impacto Socioambientais (Rosolen; Comini, 2014), sendo essa última a que será adotada nesse artigo. Os ditos Negócios Inclusivos, por sua vez, seriam a ligação da habilidade das grandes corporações atuarem na redução de desigualdades, ao incluir a base da pirâmide em seu mercado de consumo 
FREITAS, Talita da Silva Clerc; MELLO, Ruth Espíndola de. Curso de Negócios de Impacto Socioambiental da PUC Rio: uma ferramenta de fomento e disseminação do Empreendedorismo Social.

(Reficco, 2011 apud Rosolen; Comini, 2014). Portanto, embora haja variações acerca do Empreendedorismo Social, todos possuem como núcleo central um objetivo social que transforme positivamente o ambiente em que se encontram, diferenciando-se do Empreendedorismo de Responsabilidade Social e do Privado.

Os Negócios de Impacto Socioambiental possuem como princípio básico conciliar a solução de um problema social e o retorno financeiro (Barki, Comini, Torres, 2019). Após a crise da década de 2010, surge uma busca pela difusão de alteração na gestão das empresas, visando a maior preocupação com os impactos sociais e ambientais. Nesse cenário, emergiram movimentos, como o "Sistema B" e os "NIS", que defendem que as empresas são responsáveis por suas ações e devem procurar impactar positivamente a sociedade. Desse modo, são organizações híbridas, assemelhando-se ao contexto norte-americano, que integram o setor 2,5 (Barki, Comini, Torres, 2019).

No Brasil, os Negócios de Impacto Socioambiental cresceram e, com eles, surgiram aceleradoras e fundos de investimentos. Enquanto isso, na academia, cada vez mais alunos e professores demonstram interesses nesse tema. Inclusive, o próprio governo movimenta-se, ainda que lentamente, para elaborar uma estratégia pública que impulsione esses negócios (Barki, Comini, Torres, 2019), vide a "Enimpacto" do Ministério da Economia. Contudo, ainda existem desafios para esses empreendimentos, como a necessidade de inclusão na cadeia de valores de grandes empresas, maior escalabilidade, e a ausência de atuação colaborativa entre os setores. Destarte, torna-se possível afirmar que, apesar da falta de consenso entre os autores acerca da terminologia, há um denominador comum entre eles: a crença de que se pode e se deve fazer negócios de outra forma (Barki, Comini, Torres, 2019), aplicando um capitalismo movido por propósito.

\section{Educação em Negócios de Impacto Socioambiental}

O ensino é um dos caminhos para o desenvolvimento da cidadania e do empreendedorismo, logo o método deve ser muito bem escolhido. O empreendedorismo é um tema que transgride a ideia de "criar um negócio", pois engloba ultrapassar seus limites e autoconhecer-se (Bastos; Ribeiro, 2011). Com isso, torna-se fundamental ampliar o ensino sobre esse assunto, a fim de formar indivíduos com maior capacidade reflexiva sobre o tema.

A formação do empreendedor social está vinculada aos espaços e contextos de aprendizagem, segundo Itelvino et al. (2018), o que destaca a importância de fomentar cada vez mais a divulgação e construção de disciplinas de ensino médio e graduação, cursos de extensão e 
FREITAS, Talita da Silva Clerc; MELLO, Ruth Espíndola de. Curso de Negócios de Impacto Socioambiental da PUC Rio: uma ferramenta de fomento e disseminação do Empreendedorismo Social.

especializações nessa área. Além disso, é importante potencializar ações por meio de projetos e vivências (Oliveira, 2004). Contudo, há uma certa dificuldade em relação a isso, devido à falta de consenso dos autores e poucas referências na academia. No cenário dos NIS, há uma lacuna na formação, uma vez que há poucos cursos disponíveis, o que torna ainda mais difícil a divulgação dessa área e a certificação dos empreendedores. Sendo assim, a PUC-Rio inovou e empreendeu como fomentadora, ao inaugurar, no ano de 2019, um curso de extensão voltado para essa temática, permitindo uma formação mais integral do sujeito, visto que ele estabelece diferentes relações, englobando os três tipos de educação mencionados.

Portanto, são necessárias mais ações como essa, com o intuito de aprimorar a formação de empreendedores e a disseminação de conhecimento. Afinal, a educação vai além do transmitir dados e informações, uma vez que amplia a visão de mundo do aluno e o torna um indivíduo mais reflexivo, quando estimulado. Assim, ainda que muitos não tenham o desejo de seguir nessa área, o fomento ao Empreendedorismo Social permite a construção de indivíduos com uma visão mais humana e cidadã, que entendem que suas ações geram consequências no mundo, que por sua vez, gera consequências em sua vida.

\section{Método}

Para a realização deste trabalho, foi escolhida a estratégia de estudo de caso, devido à sua natureza qualitativa e exploratória, inspirada nos métodos propostos por Correia e Teixeira (2015), Forte (2006) e Lieberman (2004). A abordagem qualitativa foi adotada, pois permite uma possível investigação por meio de pesquisa documental, etnografia e estudo de caso (Godoy, 1995 apud Lieberman, 2004). Como o assunto abordado possui poucos estudos e pesquisas, optou-se por selecionar duas das três formas de investigação: a análise documental e o estudo de caso. A análise realizada teve como base os dados coletados na $3^{\mathrm{a}}$ edição do Curso de Negócios de Impacto Socioambiental da PUC-Rio, finalizada em outubro de 2020, por meio de dois relatórios, um no meio e outro no final do curso, caracterizando um estudo de caso comparativo com uma amostragem analisada em dois diferentes momentos.

Para essa coleta de dados, foi utilizado um instrumento híbrido, semelhante ao de Forte (2006), materializado em um questionário anônimo que possui perguntas fechadas com opções de resposta do tipo múltipla escolha, sendo algumas dentro do padrão likert (Likert, 1932); e abertas do tipo discursiva, além da pesquisa documental. No instrumental híbrido, todos os alunos do curso respondem, dando sua opinião sobre o curso e sua estrutura. Nos questionários da $3^{\text {a }}$ edição, diferentemente das versões anteriores, foram adicionadas algumas questões que 
FREITAS, Talita da Silva Clerc; MELLO, Ruth Espíndola de. Curso de Negócios de Impacto Socioambiental da PUC Rio: uma ferramenta de fomento e disseminação do Empreendedorismo Social.

abrangessem o impacto da proposta educacional e seus conteúdos na visão de negócios dos alunos. Essa adição visava uma comparação clara do desenvolvimento gradativo dos alunos dessa mesma edição e como o curso conseguiu influenciá-los. Além disso, foram selecionados trabalhos com o mesmo arcabouço teórico para ajudar a construir um pensamento crítico acerca da análise dos dados obtidos, visto que a quantidade de alunos é limitada, assim como o tema a que se refere. Afinal, segundo Godoy (1995 apud Lieberman, 2006), a pesquisa documental é formada pelos exames de baterias de natureza diversa, a fim de buscar interpretações novas e/ou complementares. Utilizam-se, portanto, métodos quantitativo e qualitativo, com o uso de escala likert, comparação de grupos, análise documental e estudo de casos numa perspectiva transversal, visando compreender os dados coletados do grupo da $3^{\text {a }}$ edição, utilizando ambas as técnicas para inferir como os alunos das edições do curso NIS da PUC-Rio tiveram sua visão de negócios impactada pelo contato com essa formação educacional.

\section{Análise de dados}

Como apresentado a priori, os dados foram divididos em duas coletas: a primeira formada pelos dados coletados na pesquisa intermediária (metade do curso) da $3^{\text {a }}$ edição do curso e a segunda composta pelos dados coletados ao final. Serão analisadas as respostas de quatro perguntas com respostas quantitativas e três qualitativas. Nessas primeiras, por ter sido escolhida a escala likert de 5 pontos, duas primeiras perguntas tinham como alternativa números dentre 1 a 5 , sendo 1 a menor nota, enquanto 5 , a maior. A terceira tinha como alternativa "sim" e "não", enquanto a última tinha uma escala de 5 alternativas baseada em porcentagens ( $0-20 \%$, 21-40\%, 41-60\%, 61-80\% e 81-100\%). As perguntas são: (i) "Quanto você conhecia sobre NIS antes de começar o Curso?" e "Qual o seu nível de conhecimento?"; (ii) "A té esse momento, o quanto você enxerga a aplicabilidade dos assuntos abordados?"; (iii) "Sua percepção do Mundo de Negócios mudou após o início do nosso curso?"; e (iv) "O quanto você acredita que os conteúdos estudados impactam sua carreira?”. As qualitativas, por outro lado, são compostas pela indagação de como os alunos se sentem ao começar o curso, ao estarem na metade e ao concluírem. Essa gradação de tempo foi escolhida para permitir uma compreensão do impacto do aprendizado formal (conteúdos como textos, vídeos e aulas ao vivo) e informal (trocas em grupo, tutoria e dinâmicas).

Ao analisar a primeira pergunta quantitativa, ficou evidente que a maioria dos alunos tinham conhecimentos superficiais do tema, uma vez que $87,9 \%$ afirmou estar entre 1 e 3 , numa escala de 5 pontos. No final do curso, vemos uma significativa mudança dessa noção, pois 
FREITAS, Talita da Silva Clerc; MELLO, Ruth Espíndola de. Curso de Negócios de Impacto Socioambiental da PUC Rio: uma ferramenta de fomento e disseminação do Empreendedorismo Social.

apenas $23,9 \%$ afirmavam estar entre 1-3, enquanto 76,2\% diziam ter construído um saber acerca desses temas entre 4-5, pontuações mais elevadas. Desse modo, destacando um aumento significativo do conhecimento dos alunos, que teria sido provocado pelas estratégias de educação utilizadas.

\section{Qual o seu nível de conhecimento sobre o NIS?}

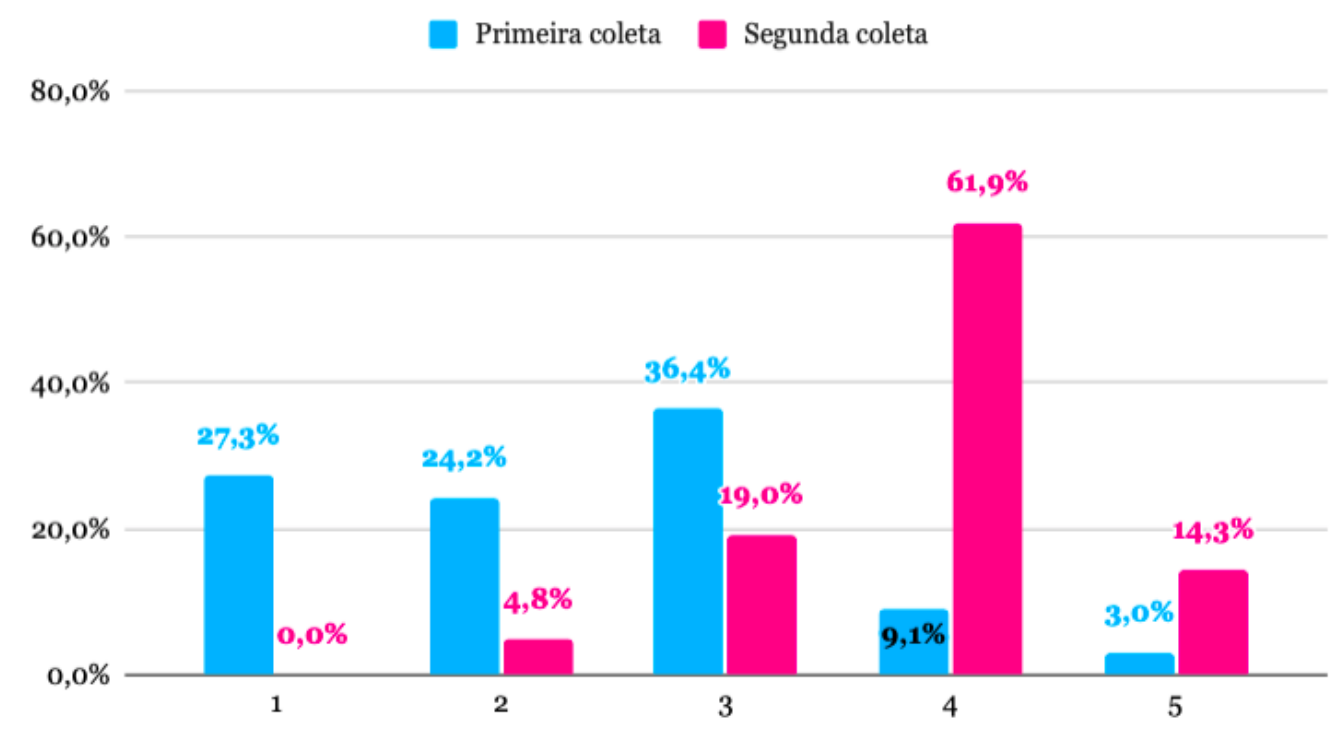

Figura 1

Na segunda pergunta, sobre a aplicabilidade, na metade do curso, os alunos afirmavam ver 78,8\% de aplicabilidade, número que subiu para 95,2\% ao final das atividades. Embora nosso primeiro dado já fosse alto, ele aumentou ainda mais, destacando assim que, com o término do curso, os alunos em sua maioria conseguiam ver formas de aplicar o que foi aprendido. Tal aplicabilidade é fruto de processos de ensino-aprendizagem bem desenvolvidos e aplicados. 


\section{Até esse momento, o quanto você enxerga que seja a aplicabilidade dos assuntos abordados?}

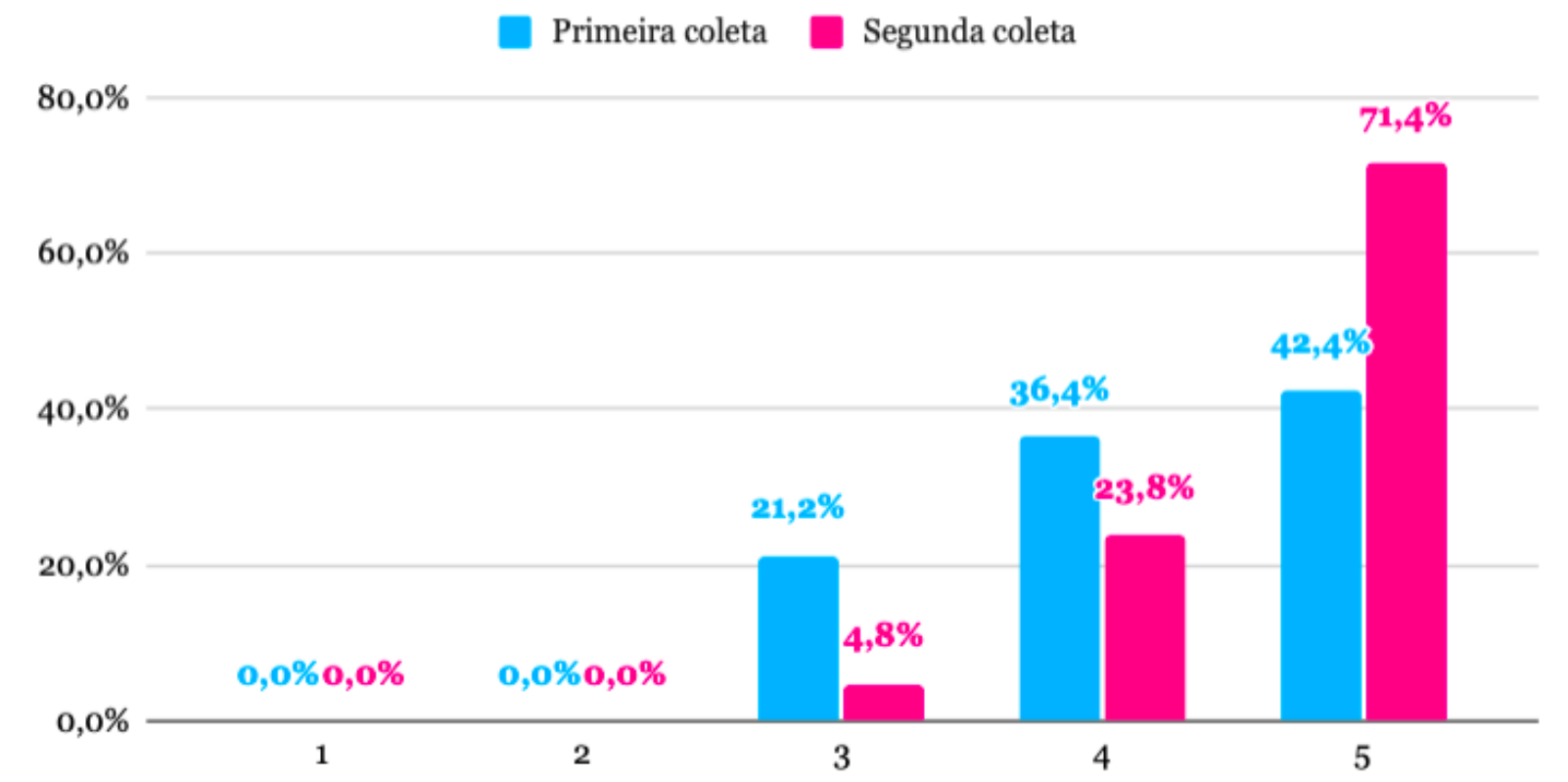

Figura 2

A pergunta três abordava a percepção do mundo de negócios ser modificado por meio do desenvolver do curso e aprendizado. Na primeira coleta, foi identificado que $87,9 \%$ tiveram sua compreensão alterada; isto é, ampliada e aprofundada sobre os temas de mercado, a partir do curso. Todavia, esse número diminuiu para $71,4 \%$ na segunda coleta. Tal redução pode ser decorrente de uma grande mudança de paradigma em primeiro momento, o que provocou uma ruptura significativa. Assim, tornando difícil haver mais um grande movimento de mudança da metade do curso para o final. 


\section{Sua percepção do Mundo de Negócios mudou após o início do nosso Curso?}

Primeira coleta $\square$ Segunda coleta

$100,0 \%$

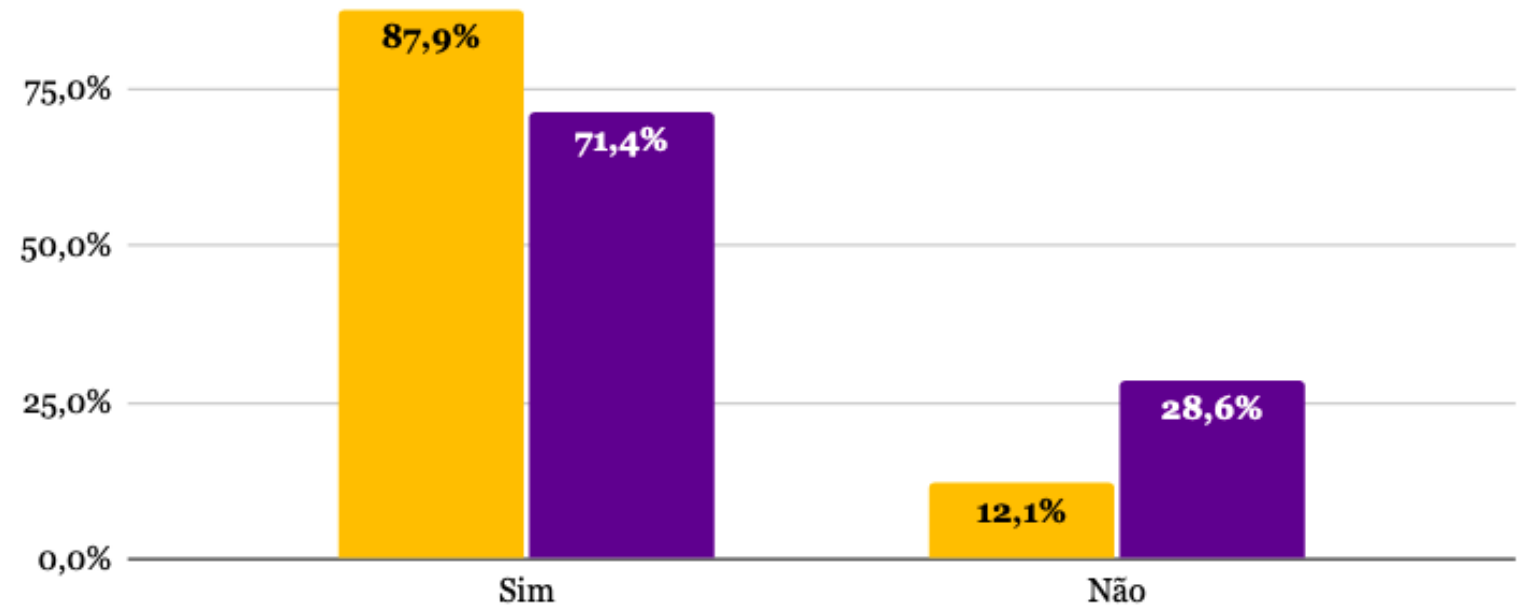

Figura 3

Ao indagar sobre o impacto dos materiais estudados em sua carreira, no primeiro momento, 30,3\% dos alunos indicaram que entre $81-100 \%$ de sua visão foi influenciada; enquanto 39,4\% afirmavam ter sofrido influência entre $61-80 \%$, os demais 30,2\% ficaram entre 21-60\%. Na segunda coleta pode ser observado um aumento significativo, porque $47,6 \%$ dos alunos declararam que tiveram suas carreiras influenciadas entre 81-100\%, aumentando em $17,3 \%$ comparado ao primeiro grupo. A porcentagem de $61-80 \%$ caiu para $33,3 \%$, ou seja, $6,1 \%$ a menos que na primeira parte, enquanto $21-60 \%$ foi reduzido para $19 \%$. Portanto, fica evidente que o Curso NIS influenciou na carreira de seus alunos, independente de sua formação e atuação profissional. 


\section{O quanto você acredita que os conteúdos estudados impactam sua carreira?}

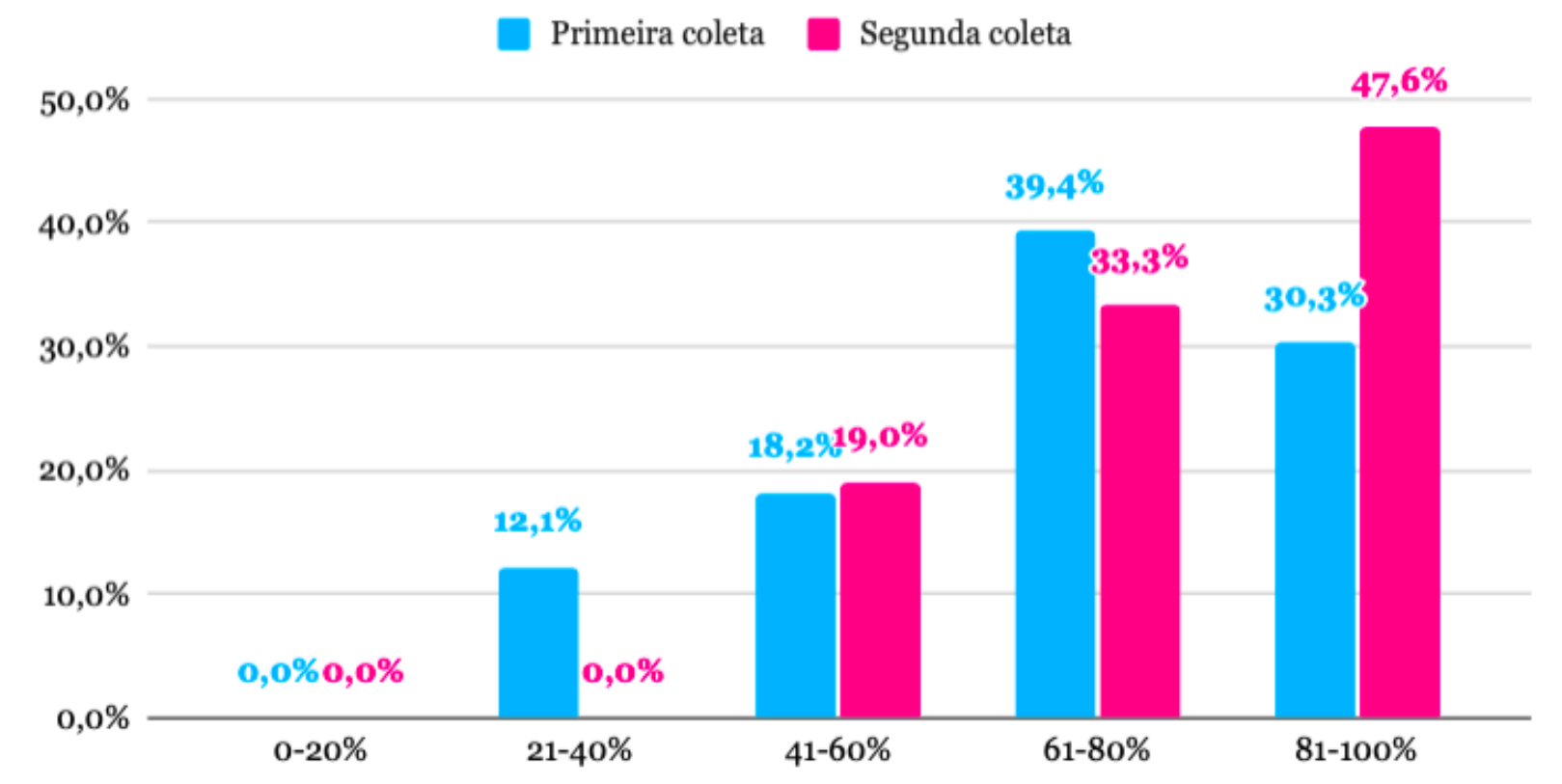

Figura 4

Por fim, nas perguntas qualitativas, pode-se compreender um predomínio de sentimentos positivos em três momentos. Num primeiro encontro, o predomínio foi de palavras como curiosidade, animação, entusiasmo, empolgação e ansiedade, o que demonstra que os alunos estavam encarando o curso de forma positiva, esperando realmente aprender novos conceitos, construir boas conexões e ter sua curiosidade satisfeita sobre esse setor tão pouco comentado. Tais explicações foram tiradas dos comentários opcionais disponibilizados. No meio do curso, houve uma predominância significativa da palavra empolgadx, sendo seguida por feliz, encantado, interessado e contempladx. Com isso, tornando visível que a expectativa estava sendo atendida e a experiência educacional estava sendo proveitosa. Na segunda coleta, ao fim do curso, as palavras em destaque foram relacionadas com satisfação, incentivo e felicidade, sendo possível ver como o curso realmente entregou o que os alunos esperavam, por isso gerou tantos sentimentos positivos. Nessa última parte, houve apenas uma palavra negativa que foi "frustrada", mas sua justificativa foi porque o aluno em questão não conseguiu ter a participação que havia desejado, o que acredita ter comprometido sua aprendizagem. Nossa equipe conversou com ele e entendeu que não havia sido uma falha do curso, mas sim das circunstâncias sanitárias em que vivíamos, quando o país inteiro estava em casa e vivendo tempos de incerteza por conta da pandemia da Covid-19. 

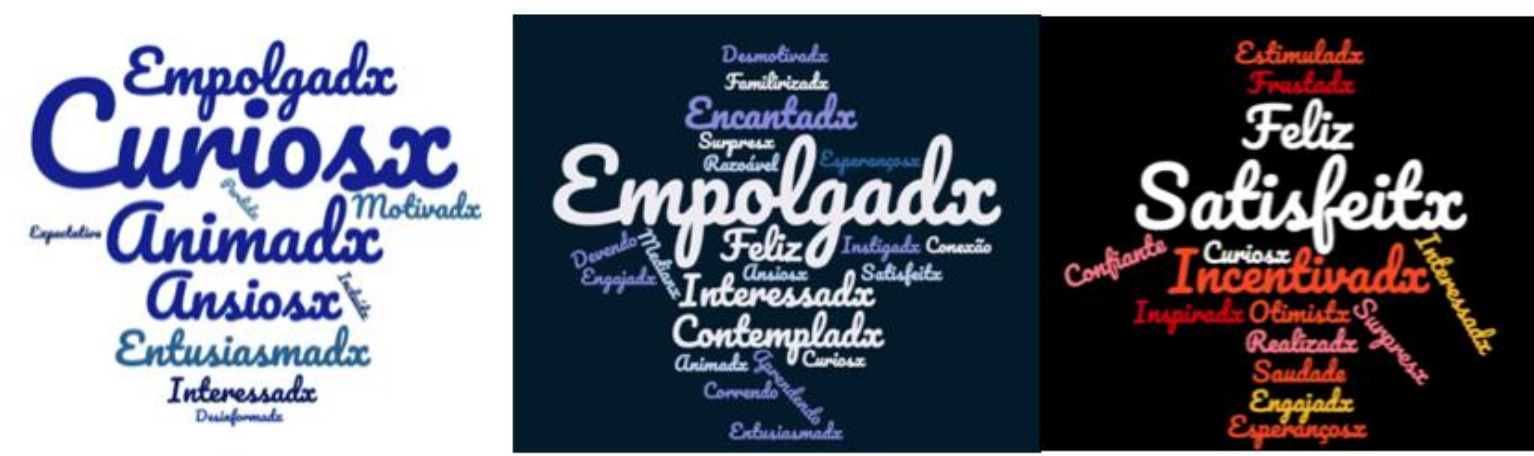

Figura 5

\section{Discussão}

Após a exposição dos resultados obtidos com o Curso NIS da PUC-Rio, torna-se claro que a educação é fundamental, conforme defendido por Paulo Freire, para mudar a visão do ser humano sobre a vida e seus processos. O curso foi desenhado, desde sua primeira edição, num formato remoto, justamente para contemplar o máximo de alunos possível. Por essa razão, com o início da pandemia, nossos processos internos não foram afetados, apesar do estado emocional de todos não ser o mesmo em decorrência do cenário global. A experiência dos alunos foi preservada de qualquer impacto técnico acerca dos recursos, uma vez que nossos encontros síncronos eram gravados a fim de permitir que os alunos que não possuíam internet no momento assistissem o material posteriormente E, além disso, foram confeccionados resumos explicativos de cada encontro, para que os alunos sem uma boa conexão de banda larga pudessem ficar cientes dos temas abordados e das questões discutidas. Desse modo, acreditase que o formato a distância de ensino pode ser inclusivo e tão eficaz quanto o presencial, se for construído pensando nas múltiplas realidades existentes em nosso país.

Um benefício oferecido pelo curso foi a multiplicidade de seus participantes - por ser num formato remoto, permitiu que pudéssemos ter alunos de quase todas as regiões do país, levando à exposição de diferentes realidades e perspectivas. Sobre os conteúdos, os alunos, em ambos os momentos de avaliação, indicaram ter sido em boa quantidade e qualidade, assegurando a robusta estrutura desenvolvida pela coordenação e corpo docente. Os encontros ao vivo foram considerados extremamente positivos, sendo descritos como excelentes oportunidades para conhecer mais sobre os temas, tirar dúvidas e aprender muito mais. Tais respostas vão ao encontro da necessidade de misturarmos o máximo de recursos possíveis, com o intuito de garantir uma boa experiência educativa, de acordo com as técnicas e conhecimentos do Design Educativo (ou Instrucional), descrito e explicado por Filatro (2019). Além dos 
FREITAS, Talita da Silva Clerc; MELLO, Ruth Espíndola de. Curso de Negócios de Impacto Socioambiental da PUC Rio: uma ferramenta de fomento e disseminação do Empreendedorismo Social.

encontros de troca (Aprendizagem Informal), os recursos assíncronos de aprendizagem (Aprendizagem Formal) possuíam formatos diversos, justamente para englobar todos os diversos perfis de aprendizes que poderíamos ter, conforme apresentado por Cavellucci (2005).

Pode-se, portanto, declarar que as experiências de aprendizagem, ainda que curtas, podem provocar uma grande mudança de mentalidade em seus alunos. Somente com a massificação de tais experiências será possível erradicar a compreensão errônea de tal ocupação ser inata para alguns e disseminar as diversas opções que esse tipo de negócio oferece. Além disso, com o aumento do número de cursos sobre esse tema, mais pessoas conhecerão os NIS, permitindo que mais jovens e adultos descubram como podem gerar lucro e impacto social ao mesmo tempo. Somente assim será possível contribuir para as mudanças que já ocorrem, já que a Geração Y, em ascensão na População Economicamente Ativa, não apenas defende os pilares de impacto socioambiental, como os têm como critério decisivo para compra ou não de produtos.

\section{Considerações finais}

O empreendedorismo é um catalisador, uma vez que possibilita uma mudança de visão que ocasiona uma mudança de comportamento. Justamente por isso, é necessário incentivar cada vez mais o surgimento de novos empreendimentos para que, aos poucos, a mentalidade social e comercial mude e a humanidade entre em harmonia com o planeta. Logo, para que isso possa ocorrer, é fundamental que essa temática se torne cada vez mais acessível e rica em informações.

O Empreendedorismo Social é uma vertente que cresceu muito na última década devido às graves mudanças ambientais e à alta desigualdade social, tendo exemplos de negócios como a Insolar (Mello et al., 2019), que evidenciam como é possível verdadeiramente conciliar o $2^{\circ}$ e $3^{\circ}$ setores. Todavia, há uma baixa oferta de cursos e disciplinas nessa área, o que restringe o acesso do público e dificulta a expansão da visão do empreendedorismo social, sendo fundamental o fomento de novas propostas de ensino que englobem essa vertente empreendedora, caso realmente se deseje mudar positivamente a sociedade como um todo.

A proposta desse trabalho foi compreender como o Curso de Extensão de Negócios de Impacto Socioambiental da PUC-Rio afetou a vida de seus alunos e auxiliou em seu desenvolvimento de carreira. Conforme levantado inicialmente, o curso e os conteúdos provocaram um grande impacto e uma transformação na maneira de enxergar o mercado e os negócios, em consonância com a ideia de que precisamos incentivar cada vez mais a criação de 
FREITAS, Talita da Silva Clerc; MELLO, Ruth Espíndola de. Curso de Negócios de Impacto Socioambiental da PUC Rio: uma ferramenta de fomento e disseminação do Empreendedorismo Social.

propostas educacionais básicas e especializadas dentro do mundo empreendedor para formar empreendedores capazes de tirar seus sonhos e ideias do papel.

Torna-se evidente que o recurso educacional realmente é uma excelente ferramenta de mudança e crescimento. Nesse sentido, deve-se investir para que o Brasil ser transforme a partir dessas vivências e conhecimentos, pois somente assim será possível mudar a realidade do nosso país desigual. Caso haja o fomento e o investimento na educação destinados ao empreendedorismo e ao empreendedorismo social, a mudança poderá ocorrer. Tal mudança transformará a visão dos alunos e dos professores envolvidos, que buscarão atuar propositivamente nesse processo de transformação, retroalimentando-o e ajudando a construir um mundo melhor, estando em concordância com a visão das novas gerações que ascendem ao mercado. O empreendedorismo social muda uma sociedade, mas tudo isso começa com uma ideia. E uma ideia é excelente, porém, uma sala repleta delas é excepcional, e no NIS isso ocorreu. Logo, por que não expandir isso? 
FREITAS, Talita da Silva Clerc; MELLO, Ruth Espíndola de. Curso de Negócios de Impacto Socioambiental da PUC Rio: uma ferramenta de fomento e disseminação do Empreendedorismo Social.

\section{Referências Bibliográficas}

BARKI, Edgard; COMINI, Graziella Maria; TORRES, Haroldo da Gama. Negócios de impacto socioambiental no Brasil. Rio de Janeiro: FGV, 2019.

BASTOS, Maria Flávia; RIBEIRO, Ricardo Ferreira. Educação e empreendedorismo social: um encontro que (trans) forma cidadãos. Revista Diálogo Educacional, v. 11, n. 33, p. 573-594, mai/ ago, 2011.

CAVELLUCCI, Lia Cristina B. Estilos de aprendizagem: em busca das diferenças individuais. Curso de Especialização em Instrucional Design, v. 33, 2005.

DEES, J. Gregory. The Meaning of Social Entrepreneurship 1, 2. Case Studies in Social Entrepreneurship and Sustainability. p. 22-30, Routledge, 2018.

FAGUNDES, Fabio Mello; FAGUNDES, Marcelo Mello. Empreendedorismo: uma revisão sobre o tema. OPET Textos, v. 1, p. 75, 2009.

FILATRO, Andrea. Design instrucional 4.0. Saraiva Educação SA, 2019.

FORTE, Claudia Marcia de Jesus. Estudo de caso comparativo entre Programas de microcrédito na América Latina: o impacto socioeconômico nas mulheres das cidades de Bogotá e Recife. Tese de Doutorado. Universidade de São Paulo, 2006.

FREIRE, Paulo; TORRES, Carlos Alberto. Diálogo com Paulo Freire. São Paulo: Loyola, 1979.

HINDLE, Tim. Guide to Management Ideas and Gurus (The Economist). New York: Harper Collins, 2008.

INSOLAR. Disponível em: 〈https://insolar.eco.br〉. Acesso em 06/11/2021.

ITELVINO, L. D. S.; COSTA, P. R. D.; GOHN, M. D. G.; RAMACCIOTTI, C. Formação do empreendedor social e a educação formal e não formal: um estudo a partir de narrativas de história 
FREITAS, Talita da Silva Clerc; MELLO, Ruth Espíndola de. Curso de Negócios de Impacto Socioambiental da PUC Rio: uma ferramenta de fomento e disseminação do Empreendedorismo Social.

de vida. Ensaio: Avaliação e Políticas Públicas em Educação, Rio de Janeiro, v.26, n. 99, p.471504, 2018.

LIBERMAN, Vitor. Empreendedorismo social: um processo em construção: estudo de caso de três empresas gaúchas. 2004.

LIKERT, Rensis. A technique for the measurement of attitudes. Archives of psychology, 1932.

MELLO, Ruth et al. INSOLAR: a Escolha da Formalização Jurídica para Negócios Sociais no Brasil. REASU-Revista Eletrônica de Administração da Universidade Santa Úrsula, v. 4, n. 1, 2019.

O CRESCIMENTO DO EMPREENDEDORISMO SUSTENTÁVEL NO BRASIL. Pensamento Verde, 25/09/2013. Disponível em: $<\underline{\text { https://www.pensamentoverde.com.br/sustentabilidade/crescimento-empreendedorismo- }}$ sustentavel-brasil/>. Acesso em: 12 set 2021.

OLIVEIRA, Edson Marques. Empreendedorismo social no Brasil: atual configuração, perspectivas e desafios - notas introdutórias. Revista da FAE, v. 7, n. 2, 2004.

ROSOLEN, Talita; TISCOSKI, Gabriela Pelegrini; COMINI, Graziella Maria. Empreendedorismo social e negócios sociais: um estudo bibliométrico da produção nacional e internacional. Revista Interdisciplinar de gestão social, v. 3, n. 1, 2014.

SCHOPENHAUER, Arthur. Parerga und Paralipomena II. Sämtliche Werke. Bd. V. 1851. 